\title{
Mathematical Modeling to Evaluate and Select the Best Coagulant in Drinking Water Treatment, using Multi-Attribute Group Decision Making
}

\author{
Mohammadreza Jabehdari ${ }^{1}$, Leila Mosleh², Seyed Hossein \\ Hashemi² $^{2}$ and Mohammadreza Sadeghi Moghadam ${ }^{1}$ \\ ${ }^{1}$ Department of Industrial Management, University of Tehran, Tehran, Iran \\ ${ }^{2}$ Department of Environmental Pollutant, Environmental Sciences Research Institute, \\ Shahid Beheshti University, Tehran, Iran
}

\section{Research Article \\ Volume 2 Issue 1}

Received Date: January 25, 2019

Published Date: February 12, 2019

DOI: $10.23880 /$ oajwx-16000116

*Corresponding author: Mohammadreza Jabehdari, Department of Industrial Management, University of Tehran, Tehran, Iran, Email: mr.jabedari@gmail.com

\begin{abstract}
Urbanization, population growth, and changing the social attitude toward water consumption has increased the drinking water demand. Coagulation is one of the essential processes in drinking water treatment plants in which the particles and microorganisms attached to those particles are settled down and removed. While there are different kinds of coagulants and coagulant aids are being used in drinking water treatment plants, it is always important to select the best available options considering important factors (criteria) such as efficiency, cost, and effect on health and environment. These three criteria are used to compare three alternatives including ferric chloride, poly aluminum chloride, and alum associated with corn starch as a coagulant aid. To find the best coagulant combination, we performed multi-attribute group decision making (MAGDM) using the conventional Cook and Seiford method. After mathematical modeling, Hungarian method was used to solve the problem. Then, the priority among the coagulants was determined based on defined criteria. The results of this article showed that ferric chloride and corn starch was ranked first among the alternatives. Poly aluminum chloride and alum with corn starch was ranked second and third respectively. The analysis and results presented in this article have significant implications for different operating strategies and material selection in water treatment plants.
\end{abstract}

Keywords: Coagulation; Multi-Attribute Group Decision Making; Mathematical Modeling; Ranking 


\section{Open Access Journal of Waste Management \& Xenobiotics}

\section{Introduction}

Urbanization, population growth, and changing the social attitude toward water consumption has increased the drinking water demand [1,2]. In addition to demand increase, having access to high water quality is vital to avoid waterborne diseases. Drinking water treatment usually comprises coagulation, sedimentation, filtration, and disinfection. Coagulation is one of the essential processes in drinking water treatment in which the particles and microorganisms attached to those particles are settled down and removed [3,4]. Recently, several studies have shown the capability of natural coagulants as an eco-friendly solution to reduce the amount of chemical coagulant in the process of water treatment. Such solutions have been recognized as cost-effective solutions compare to the conventional chemical coagulant. However, a natural coagulant is not always as efficient as chemical coagulants and studies have shown that a combination of natural and chemical coagulants can provide more efficient options [5-7]. Using the combination of natural and chemical coagulants both increases the efficiency of water treatment and decreases the adverse health effects of chemical residual on human and aquatic creatures [8]. Comparing the efficiency of coagulants in drinking water treatment enable us to select the coagulant (or a combination of coagulants) that works the best for a treatment plant. Few studies have been done on comparing the efficiency of coagulants. Torabiyan, et al. examined the performance of poly aluminum chloride (PAC), aluminum sulfate, and ferric chloride in conventional treatment processes. They showed that PAC has the greater ability in reducing the turbidity of water, especially at higher turbidity. Mizanzade \& Mostafayi compared the impact of ferric sulfate, ferric chloride and alum with using lime as a coagulant aid. Ganjidust, et al. compared synthetic and natural polymers and showed that lime with chitosan has an ability in purifying water. Therefore, it is necessary to compare coagulants to find the most effective combination. However, in previous papers, only the factor of efficiency was considered for the comparison among different types of coagulants. Thus, there is an obvious need to incorporate other criteria that are important for decision-making in drinking water treatment facilities. Other factors such as costs, health and environmental effects are crucial in addition to efficiency. Thus, in this paper, we used multi-attribute decision making (MADM) to come up with the best solution considering various essential criteria. Considering different factor is not always easy in the decision-making process as there might be conflict among the criteria that increases the complexity. Thus, methods such as MADM have been introduced to assist managers in making correct decisions $[9,10]$. Multi-attribute group decision making (MAGDM) is a type of MADM that we incorporate the multiple experts' opinion. In group decision making method, various attributes are considered, and the most appropriate alternative can be selected at the end based on the comparisons of sets of alternatives. Selection of the best option is based on the mathematical equation [11].

The primary objective of this paper is to provide a tool for decision-makers in drinking water treatment facilities to identify the best coagulant alternative among the possible options. To reach this objective, four steps are proposed: (1) select the coagulants or coagulants combination of interest as the set of alternatives (2) identify the critical criteria for decision-making among the alternatives (3) provide values for each criterion using various methods including lab experiment, expert opinion, and literature (4) using MAGDM method to select the best alternative.

\section{Materials and Methods}

According to Wacker this paper can be considered as an analytical mathematical research [12]. The methodology is divided into three main parts. Initially, we selected criteria that are important in the process of decision making for drinking water facilities. Obviously, efficiency is one of the important criteria that need to be considered for an effective treatment process. Also, Cost is always an important factor for decision making and is always important for comparing various alternatives. In addition, residual of chemical in the treated water may cause health and environmental concern and needs to be considered as one of the criteria. First, experimental data was gathered through a series of lab work on coagulation/ flocculation process. Second, literature and documents on adverse health effects of the coagulants residual in water was collected. Third, the cost of the coagulants is compared based on the available price in the market. Finally, all the mentioned information was provided to experts for reaching their opinion. Then, ranking methodology was applied to select the best combination.

\section{Criteria Selection}

\section{Efficiency}

Aluminum and iron-based coagulants are among the conventional and available coagulants that are widely used for water treatment. Among these materials, 
aluminum sulfate (alum), poly aluminum chloride (PAC), and ferric chloride are very popular [13]. Thus, we used these three coagulants as the target coagulants for this research. The turbidity removal efficiency data from these three common coagulants carried out from Mosleh, et al. [3]. In this study synthetic initial turbidity of 250 nephelometric turbidity unit (NTU), and 500 NTU were created using clay. Three types of chemical coagulants were used in the lab experiments including PAC, ferric chloride, and alum. Three doses of $1 \mathrm{ppm}, 2 \mathrm{ppm}$, and 3 ppm were used for chemical coagulants. Corn starch was used as a natural coagulant (coagulant aid) with three different doses of $0.1 \mathrm{ppm}, 0.3 \mathrm{ppm}, 0.5 \mathrm{ppm}$, and $0.7 \mathrm{ppm}$.
Jar test was used for the flocculation process. Three replicates were used for each set of experiment. The percent of turbidity removal was calculated as shown in equation 1:

\section{Equation 1}

$\%$ Turbidity removal $=\left(\frac{\text { Initial turbidity }- \text { Final turbidity }}{\text { Initial turbidity }}\right) \times 100$

Among all the tests we performed, the maximum efficiency and turbidity removal were listed in Table 1. We provided the results of this table to expert as a source for ranking the efficiency of coagulants and coagulant aid combination.

\begin{tabular}{|c|c|c|c|c|c|}
\hline Chemical coagulant & $\begin{array}{c}\text { Dose of chemical } \\
\text { coagulant (ppm) }\end{array}$ & Coagulant aid & $\begin{array}{c}\text { Dose of coagulant } \\
\text { aid (ppm) }\end{array}$ & $\begin{array}{c}\text { Initial turbidity } \\
\text { (NTU) }\end{array}$ & $\begin{array}{c}\text { Mean of turbidity } \\
\text { removal (\%) }\end{array}$ \\
\hline PAC & 5 & Corn starch & 0.7 & 250 & 98.48 \\
\hline Ferric chloride & 5 & Corn starch & 0.7 & 250 & 98.37 \\
\hline Alum & 5 & Corn starch & 0.5 & 250 & 92.54 \\
\hline Ferric chloride & 5 & Corn starch & 0.7 & 500 & 98.52 \\
\hline PAC & 5 & Corn starch & 0.5 & 500 & 98.38 \\
\hline Alum & 5 & Corn starch & 0.7 & 500 & 95.83 \\
\hline
\end{tabular}

Table 1: Maximum Turbidity Removal in Various Coagulants Combination [3].

As Table 1 represents, the efficiency of various coagulants combination in various initial turbidity is different. Thus, deciding what type of coagulant is a better option to use according to efficiency and dose of coagulants are needed to be investigated with experts. Thus, we asked the experts to rank the coagulants based on the results of previous studies including Mosleh, et al. and other available papers on this topic as the performance of coagulants might differ in various initial assumptions [3].

\section{Health and Environmental Impact}

In the process of coagulation and flocculation, the compounds comprising $\mathrm{Al}$ such as aluminum sulfate (alum), and PAC can alter the surface charge of suspended solids and promote agglomeration to bigger flocs and finally enhance sedimentation of particles [14-16]. Although Al-based coagulants can improve the coagulation process, it can cause some potential adverse effects such as Alzheimer's disease [17-19]. In addition, Al is broadly diffused in water and can cause toxicity as there are regulations and standards to control $\mathrm{Al}$ level in drinking water. Although ferric chloride and usually ironbased coagulants have impurities, the level of impurities can cause adverse health effect or environmental impacts such as lead and copper corrosion of drinking and wastewater collection systems. However, if the level of impurities can be controlled, the adverse impact decreases but the price can also increase [14]. To minimize the damage, there are defined standards for the remaining residual in treated water [20]. However, there are no documented health and environmental effect comparison of various coagulants. Thus, to be able to rank considering both health and environmental impact, we need to use the expert opinions in environmental health and in the field of water treatment to rank the overall health and environmental effects of different types of coagulants by consideration of trade-offs. The health and environmental ranking data were carried out using expert opinion through the individual interview. Five experts were selected and during the interview we asked them to rank the coagulants based on the effect on the human's health and environmental impact. The standards of the coagulants listed in the material safety data sheets were given to decision makers to better decide among the options. The reason this criterion is considered as a standard is that of the importance of the subject and the diseases that could play an important role in choosing a coagulant [17]. As Table 1 represents, the efficiency of various coagulants combination in various initial turbidity is different. Thus, we need experts' opinion to be able to decide what type of coagulant is the best option. Thus, we asked the experts to rank the coagulants based on the results of previous studies including Mosleh, et al. and 


\section{Open Access Journal of Waste Management \& Xenobiotics}

other available papers on this topic as the performance of coagulants might differ in various initial assumption [3].

\section{Cost}

According to the available data in the market and prices for these coagulants, a certain proportion is available for the price. The ratios for PAC, alum, and ferric chloride are $0.75,0.15$, and 0.10 respectively. It should be noted that the coagulant usage for turbidity removal standards for drinking water (5 NTU) is not the only parameter for determining the final cost of water treatment using coagulants, the price of coagulants especially for ferric chloride is very dependent on the purity percentage and there is a tradeoff between price and residual existence in the treated water as it might cause corrosion to the assets [17]. Also, the amount of coagulant needed to reach the desired turbidity needs to be considered. As the cost depends on multiple factors, we asked the experts to rank the coagulants considering different factors affecting the total price including direct and indirect price.

\section{Priority Ranking and Consensus Formation}

We used Cook and Seiford method for priority ranking and consensus formation [21]. Through this method, we used mathematical modeling for decision-making in the selection and ranking of a coagulant combination. Afterward, decision matrices forming assignment problem was solved by Hungarian method. Finally, the final priorities were identified. We used Cook and Seiford method as we wanted to rank $m$ options by $\mathrm{k}$ decision makers (DM) [21]. The steps of this method are as follows:

- First, the opinion of each $k$ decision maker was taken. The idea must be as preferred or rating.

- Second, for each attribute a compromise agreement should be calculated for $k$ decision. Cook and Seiford for this purpose minimized disagreements between ratings with the help of a metric or distance function.

- If we consider $a_{p i}$ as preference of $p$ th DM (between $k$ DM) for ith rank (between $m$ rank) and $a_{i}$ shows an agreement rank for the selected option, then below absolute value from group disagreement (GD) should be minimized. Equation 2 shows Individual disagreement from rank agreement.

\section{Equation 2}

$\left\{d p=\sum_{i=1}^{m}\left|\mathrm{a}_{\mathrm{pi}}-\mathrm{a}_{\mathrm{i}}\right|, \mathrm{p}=1,2, \quad 3 \ldots, \mathrm{k}\right\} \quad$ (Individual disagreement from rank agreement)

Therefore, we can calculate GD $\Rightarrow d=\sum_{p=1}^{k} d_{p}=$

$$
\sum_{p=1}^{k} \sum_{i=1}^{m}\left|\mathrm{a}_{\mathrm{pi}}-\mathrm{a}_{\mathrm{i}}\right|, \ldots
$$

If $\mathrm{r}=a_{i},(\mathrm{r}=1,2,3 \ldots, \mathrm{m})$ then :

$$
\left\{d=\sum_{i=1}^{m} d_{i, r} \stackrel{r=1,2,3, \ldots, m}{\Longrightarrow} d_{i, r}=\sum_{p=1}^{k}\left|\mathrm{a}_{\mathrm{pi}}-\mathrm{r}\right|\right\}
$$

Then, the equation 3 has been used to create the following assignment problem according to the $\mathrm{H}_{\mathrm{m}^{*} \mathrm{~m}}$ permutation matrices to access group agreement from rankings:

\section{Equation 3}

$$
\begin{aligned}
& \min =\sum_{i=1}^{m} \sum_{r=1}^{m} d_{i, r} \times h_{i, r} \\
& \text { s.t: } \\
& \sum_{i=1}^{m} h_{i, r}=1, r=1,2,3 \ldots, m \\
& \sum_{r=1}^{m} h_{i, r}=0, i=1,2,3 \ldots, m \\
& h_{i, r}=\{0,1\}
\end{aligned}
$$

That $d_{i, r}$ is a deviation between one selected rank, $m$ assumed rank from $i_{\text {th }}$ purpose and $h_{i, r}$ if $i_{\text {th }}$ purpose allocated to $r_{\text {th }}$ rank equal one and otherwise equal zero. Cook and Sieford showed that the assignment method provides an easy solution that is useful when the same rank or two equal ratings (complete rank) are not desired [9].

\section{Results and Discussion}

The important criteria determined for selection of the appropriate coagulant combination are the efficiency in water turbidity removal, the risk to human health and environment, and total cost. These are among the most important parameters for determining suitable coagulants in the decision-making process. As it is shown in Table 1, the best efficiency achieved when we used both chemical and natural coagulants. Therefore, we just selected the combination of the chemical and natural coagulants which was corn starch $0.7 \mathrm{ppm}$. For each of the following coagulant an icon was assigned:

Alum + corn starch $=\mathrm{c}_{1}$

Ferric chloride + corn starch $=\mathrm{c}_{2}$

$\mathrm{PAC}+$ corn starch $=\mathrm{c}_{3}$ 


\section{Open Access Journal of Waste Management \& Xenobiotics}

The experts were asked to rank the coagulant using the available information, previous results, and their expertise. The experts ranking for each coagulant regarding various criteria including cost, efficiency, and health and environmental effect are listed in Table 2.

\begin{tabular}{|c|c|c|c|c|c|c|c|c|c|c|c|c|c|c|c|c|c|}
\hline Criterion 1 & \multicolumn{5}{|c|}{ Expert Ranking } & Criterion 2 & \multicolumn{5}{|c|}{ Expert Ranking } & Criterion 3 & \multicolumn{5}{|c|}{ Expert Ranking } \\
\hline Cost & 1 & 2 & 3 & 4 & 5 & Efficiency & 1 & 2 & 3 & 4 & 5 & Health & 1 & 2 & 3 & 4 & 5 \\
\hline First & $c_{3}$ & $\mathrm{c}_{2}$ & $\overline{c_{2}}$ & $\mathrm{c}_{2}$ & $\overline{c_{1}}$ & First & $c_{3}$ & $\mathrm{c}_{3}$ & $\mathrm{c}_{2}$ & $\mathrm{c}_{3}$ & $\mathrm{c}_{2}$ & First & $\mathrm{c}_{2}$ & $\mathrm{c}_{1}$ & $c_{3}$ & $c_{3}$ & $\mathrm{c}_{2}$ \\
\hline Second & $\mathrm{C}_{2}$ & $\mathrm{c}_{1}$ & $\mathrm{C}_{3}$ & $\mathrm{C}_{1}$ & $\mathrm{C}_{2}$ & Second & $\mathrm{C}_{2}$ & $\mathrm{C}_{2}$ & $\mathrm{c}_{3}$ & $\mathrm{c}_{1}$ & $\mathrm{c}_{1}$ & Second & $\mathrm{c}_{1}$ & $\mathrm{C}_{2}$ & $\mathrm{C}_{2}$ & $\mathrm{c}_{1}$ & $\mathrm{c}_{3}$ \\
\hline Third & $\mathrm{c}_{1}$ & $\mathrm{c}_{3}$ & $\mathrm{c}_{1}$ & $\mathrm{C}_{3}$ & $\mathrm{c}_{3}$ & Third & $\mathrm{c}_{1}$ & $\mathrm{c}_{1}$ & $\mathrm{c}_{1}$ & $\mathrm{C}_{2}$ & $c_{3}$ & Third & $c_{3}$ & $\mathrm{c}_{3}$ & $\mathrm{c}_{1}$ & $\mathrm{C}_{2}$ & $c_{1}$ \\
\hline
\end{tabular}

Table 2: Ranking Experts' Opinion on Various Criteria.

After preparing the matrices elements corresponding to arithmetic mean and lack of disagreement matrices compromise, the compromise agreement achieved in the absence of the final matrices is as follows in Table 3.

\begin{tabular}{|c|c|c|c|}
\hline Coagulant Rank & $\mathbf{1}$ & $\mathbf{2}$ & $\mathbf{3}$ \\
\hline First & 6.6 & 3.3 & 5 \\
\hline Second & 3 & 2.6 & 3.3 \\
\hline Third & 3.3 & 6.6 & 5 \\
\hline
\end{tabular}

Table 3: Compromise Agreement Matrices for Three Criteria.

In this step, the matrices for mathematical modeling are used based on disagreement compromise matrices:

$\min :\left\{6.6 h_{1,1}+3.3 h_{1,2}+5 h_{1,3}+3 h_{2,1}+2.6 h_{2,2}+3.3 h_{2,3}\right.$ $\left.+3.3 h_{3,1}+6.6 h_{3,2}+5 h_{3,3}\right\}$

s.t:

$6.6 h_{1,1}+3 h_{2,1}+3.3 h_{3,1}=1$

$3.3 h_{1,1}+2.6 h_{2,1}+6.6 h_{3,1}=1$

$5 h_{1,1}+3.3 h_{2,1}+5 h_{3,1}=1$

$h_{i,}=\{0,1\}$

The model problem was solved using the Hungarian model as the investigated problem is a minimization one. Therefore, in the first step, the least amount of each row is subtracted from the other options. Step 1 is shown below.

$$
\left|\begin{array}{ccc}
1.7 & 0 & 3.3 \\
0.7 & 0 & 0.4 \\
1.7 & 3.3 & 0
\end{array}\right|
$$

Subtracting the minimum value of the other elements from the second column is shown below.

$$
\left|\begin{array}{ccc}
1 & 0 & 3.3 \\
0 & 0 & 0.4 \\
1 & 3.3 & 0
\end{array}\right|
$$

Because the zeros can be brought together with the three vertical or horizontal zeros, the allocation problem is resolved. The coagulant is prioritized as follows in Table 4.

\begin{tabular}{|c|c|c|}
\hline Symbol & Coagulants & Rank \\
\hline $\mathrm{c}_{2}$ & Ferric chloride & First \\
\hline $\mathrm{c}_{3}$ & PAC & Second \\
\hline $\mathrm{c}_{1}$ & Alum & Third \\
\hline
\end{tabular}

Table 4: Prioritization of Coagulants.

As shown in the matrices of each of the criteria, each coagulant has advantages and disadvantages from the decision makers' perspective. Overall, ferric chloride was assessed as the best coagulant PAC as the second, and alum as the third one. This research sought to study conditions as close to the real situations as possible to reach better evaluation and results. The cost is always one of the most critical factors for managers in the decisionmaking process. In some cases, one option could make a significant difference regarding quality over the other options. However, a manager may choose a cheaper one due to financial limitations. Decision-making approach considering important criteria rather than only one factor should be viewed as a way that provides a better option compared to conventional coagulant selection. Yet, the method used in this paper can be improved by using a higher number of experts and giving weight to certain criteria based on importance.

\section{Conclusion}

The real-world decision-making issues usually consist of multiple dimensions that due to the ill-structured functions, most of the time essential criteria are getting neglected. In addition to this, most of the time more than one decision maker is affecting the process. Thus, reaching a consensus can be a challenge in such environments. Considering the complexity of these issues 
coping with multi-attribute situation needs a multiattribute decision-making process. One of the remarkable conclusions derived from the present study is the fact that there are specific criteria such as health and environmental impact that are usually neglected in the process of selecting the right coagulants. Thus, using multiple criteria and involving experts is one of the best ways to include all the necessary factors affecting a water treatment process and beyond. Although there are advantages and disadvantages associated with each coagulant, experts' opinion and their experience can be useful for the final decision. In this research, the results are based on the decision makers' opinion, and it may be considered less reliable than experimental methods. However, these decision makers benefit from valid test results and have related experience with similar tests and a good sense of using coagulants in different experiments. This method of ranking for coagulants can be used for the other coagulants and coagulants combinations. The analysis and results presented in this article have significant implications for different operating strategies and material selection in water treatment plants. It provides a framework in which expert assessment could be established for an appropriate decision making.

\section{Acknowledgment}

The lab experiments have been done in Environmental Sciences Research Institute at Shahid Beheshti UniversityTehran, Iran. The authors would like to thank Drs. Kouros Khoshbakht, Reza Deihimfard, and Afsaneh Shahbazi for their guidance during lab experiments and analysis on coagulation process.

\section{References}

1. Mosleh L, Negahban-Azar M (2017) A Practical Review of Integrated Urban Water Models: Applications as Decision Support Tools and Beyond. In AGU Fall Meeting Abstracts.

2. Abdi R, Yasi M (2015) Evaluation of environmental flow requirements using eco-hydrologic-hydraulic methods in perennial rivers. Water Science and Technology 72(3): 354-363.

3. Mosleh L, Hashemi SH, DeihimFard R, Khoshbakht K, Shahbazi A (2014a) Comparison of the Performance of Corn Starch Coagulant Aid Accompany with Alum, Polyaluminum Chloride and Ferric Chloride Coagulants in Turbidity Removal from Water. Journal of Environmental Health Enginering 1(4): 248-258.
4. Miller SM, Fugate EJ, Craver VO, Smith JA, Zimmerman JB (2014) Toward understanding the efficacy and mechanism of Opuntia spp. as a natural coagulant for potential application in water treatment. Environmental science \& technology 42(12): 42744279.

5. Oladoja NA (2015) Headway on natural polymeric coagulants in water and wastewater treatment operations. Journal of Water Process Engineering 6: 174-192.

6. Mosleh L, Hashemi SH, Khoshbakht K, DeihimFard R, Shahbazi A (2014b) Comparison of the Performance of Poly Aluminum Chloride with Natural Cocoagulants in Removal of Turbidity from synthetic aqueous solution. Journal of Environmental Health Enginering 1(3): 171-179.

7. Matilainen A, Vepsäläinen M, Sillanpää M (2010) Natural organic matter removal by coagulation during drinking water treatment: a review. Advances in colloid and interface science 59(2): 189-97.

8. Choy SY, Prasad KM, Wu TY, Ramanan RN (2015) A review on common vegetables and legumes as promising plant-based natural coagulants in water clarification. Int J Environ Sci Technol 12(1): 367-390.

9. Asgharpour, MJ (2002) Group decision making and game theory with the attitude of Operations Research: University of Tehran Press.

10. Xu Z (2015) Uncertain multi-attribute decision making: Methods and applications. Springer.

11. Qodsypour H (2001) Data analytic hierarchy process AHP: Amir Kabir University Press.

12. Wacker JG (1998) A definition of theory: research guidelines for different theory-building research methods in operations management. Journal of operations management 16(4): 361-385.

13. Niquette P, Monette F, Azzouz A, Hausler R (2004) Impacts of substituting aluminum-based coagulants in drinking water treatment. Water Quality Research Journal 39(3): 303-310.

14. Zhao H, Hu C, Liu H, Zhao X, Qu J(2008) Role of aluminum speciation in the removal of disinfection byproduct precursors by a coagulation process. 


\section{Open Access Journal of Waste Management \& Xenobiotics}

Environmental science \& technology 42(15): 57525758.

15. Gao BY, Wang Y, Yue QY (2005) The chemical species distribution of aluminum in composite flocculants prepared from polyaluminum chloride (PAC) and polydimethyldiallyl ammonium chloride (PDMDAAC). Acta hydrochimica et hydrobiologica 33(4): 365-371.

16. Yang Z, Gao B, Yue Q (2010) Coagulation performance and residual aluminum speciation of $\mathrm{Al} 2$ (SO4) 3 and polyaluminum chloride (PAC) in Yellow River water treatment. Chemical Engineering Journal 165(1): 122-132.

17. (2008) WHO Guidelines for drinking water quality. Vol 1: recommendations, World Health Organization, Genva.
18. Srinivasan PT, Viraraghavan $\mathrm{T}$, Subramanian KS (1999) Aluminium in drinking water: An overview. Water SA 25(1): 47-55.

19. Gauthier E, Fortier I, Courchesne F, Pepin P, Mortimer J, et al. (2000) Aluminum forms in drinking water and risk of Alzheimer's disease. Environ Res 84(3): 234246.

20. Moudgil B, Somasundaran P (1986) Flocculation, sedimentation and consolidation. Proceedings of the Engineering Foundation Conference Held at the Cloister, Sea Island, Georgia, USA.

21. Cook WD, Seiford LM (1978) Priority ranking and consensus formation. Management Science 24(16): 1721-1732. 